\title{
Role of Multidetector Computed Tomography (MDCT) in Evaluation of Lung Nodule with Histopathological Correlation
}

\author{
Jagmohan Gupta, ${ }^{1}$ Parul Gupta, ${ }^{2}$ Suresh Chandra Gupta, ${ }^{3}$ Amit Tak
}

\begin{abstract}
Background: Lung cancer is the most common and lethal cancer around the world. Computed tomography (CT) is an integral imaging technique for staging the lung cancer. Aim of this study was to correlate the multidetector CT (MDCT) findings of lung nodule with histopathological examination, as well as to assess the diagnostic accuracy of MDCT in evaluation of suspected lung nodule.

Methods: One hundred patients with clinical or radiological suspicion of lung nodule referred for CT scan of thorax were included in the study. Histopathological analysis was performed. The location of the lesion was analysed and nodules were classified. Fine needle aspiration cytology (FNAC) was done with spinal needle under all aseptic precautions. The results obtained by MDCT were analysed and compared with histopathological findings done by CT guided FNAC.

Results: Average age of patients was 65 years, $25 \%$ were females and $75 \%$ were males. Among all the patients $66 \%$ of lesions were located in right side lung and $34 \%$ of lesions were left in location. Of all, $2 \%$ patients had lesions less than 3 $\mathrm{cm}, 11 \%$ patients had lesion between $3-4 \mathrm{~cm}, 19 \%$ patients had lesion between $4-5 \mathrm{~cm}, 26 \%$ patients had lesion between $5-7 \mathrm{~cm}$ and $42 \%$ patients had lesion greater than $7 \mathrm{~cm}$. Many of these patients also presented with enlarged lymph nodes, most commonly mediastinal (73\%) followed by subcarinal (51 \%), hilar (44\%) and supraclavicular (4\%) lymph nodes. The most common histological findings of lung nodules analysis were adenocarcinoma (41\%). Among the 100 patients $58 \%$ had lesions located peripherally while $42 \%$ had central lesions. CT was a highly sensitive (95.45\%) and moderately specific (75\%) test and also had a high positive predictive value (96\%) to diagnose malignant lung nodule. Conclusion: CT guided FNAC of lung nodule is a safe, minimal invasive procedure with a high diagnostic accuracy. The use of CT - guided FNAC in hilar and mediastinal nodules can avoid unnecessary exploratory surgery for staging and also diagnosis could be made with lesser cost.
\end{abstract}

Key words: MDCT; Fine needle aspiration cytology; Lung cancer; Sensitivity; Positive predictive value.
(1) Department of Radiology, Government Medical College, Bharatpur, Rajasthan, India.

(2) Department of Microbiology, Government Medical College, Bharatpur, Rajasthan, India

(3) Department of Radiology, Mahatma Gandhi Medical College \& Hospital, Jaipur, Rajasthan, India.

(4) Department of Physiology, RVRS Medical College, Bhilwara, Rajasthan, India.

Correspondence: JAGMOHAN GUPTA

E: drjmgupta@gmail.com T: +919460876928

ARTICLE INFO

Received: 19 April 2021

Revision received: 26 September 2021 Accepted: 26 September 2021

\section{Introduction}

Lung cancer is among the most common and lethal cancer around the world. It represents about $13 \%$ of the new cancer cases and up to $28 \%$ of the cancer deaths. ${ }^{1}$ Most lung cancers are direct- ly attributed to smoking. Lung is also the most common site of metastatic involvement from other extra thoracic malignancies; 20 to $54 \%$ of extra-thoracic malignancies have pulmonary 
metastatic disease. A wide variety of imaging techniques are currently available for detection, diagnosis and management of lung cancer. Chest imaging is the primary modality for detection of lung nodules and masses. Computed tomography (CT) and positron emission tomography (PET) are most commonly used imaging modalities for further characterisation and to define extent of malignancy. Along with non-radiological modalities, CT is used for pre-treatment staging of the lung malignancies. Imaging is also required to assess the response to non-surgical treatment and for follow up in treated patients.

CT is more accurate for detection of a small lung nodule and it is a modality of choice for evaluation and classification of lung cancer. ${ }^{2} \mathrm{CT}$ is an integral imaging technique for staging the lung cancer. Multidetector CT (MDCT) accurately stages the tumour due to the superior multiplanar reformatted images. ${ }^{3}$ Till now there is no state sponsored lung screening program in India. This is partly attributed to high prevalence of granulomatous disease (tuberculosis - TB) in India, in which imaging finding may mimic early cancers resulting in significant anxiety and consequently usage of more invasive tests to prove the nature of these nodules; and also due to lack of availability of sufficient imaging, pathology and surgical facilities.

The merits of CT in intrathoracic scanning are innumerable. The most important among them, is the ability to evaluate lung lesions on its own and to differentiate them in terms of benign and malignant with reasonably high degree of accuracy. With this background the present study was undertaken to establish the role of CT in comprehensive evaluation of lung neoplasia, especially in Indian set-up and to study the efficacy and safety of CT-guided biopsy.

Aim of this study was to correlate the MDCT findings of lung nodule with histopathological examination, as well as to assess the diagnostic accuracy of MDCT in evaluation of suspected lung nodule.

\section{Methods}

This was a hospital based observational study. One hundred patients with clinical or radiologi- cal suspicion of lung nodule referred for CT scan of thorax to the Department of Radio-Diagnosis, Mahatma Gandhi Medical College and Hospital, Jaipur (Rajasthan) were included in the study. Histopathological analysis was performed. Study was approved by Ethic committee of the Hospital.

Data was collected from all cases of suspected lung nodule in a specified form. X-ray was done by X-ray machine Allenger-500/800 MA and a contrast enhanced CT was performed with a 128 slice GE Optima 660 scan machine.

For CT evaluation, the standard protocol involved scanning the entire thorax from the lung apices to the costophrenic angles in supine position. Further thin sections were taken in the region of interest to eliminate partial volume averaging depending on the size of the lesion.

Both non-contrast and contrast enhanced scans were performed in most cases. Used contrast was non-ionic, water soluble, Iohexol $350 \mathrm{mg} \mathrm{I} /$ $\mathrm{mL}$. The dose of contrast was $1-2 \mathrm{~mL} / \mathrm{kg}$ body weight administered by rapid intravenous bolus injection. Scanning began immediately after administration of the contrast injection.

The location of the lesion was analysed and nodules were classified. Fine needle aspiration cytology (FNAC) was done with Spinocan ${ }^{\circledR}$ spinal needle under all aseptic precautions. The lesion identified on CT and the site of entry was noted. Two to four $\mathrm{mL}$ of local anaesthesia was injected at the site after 2-3 min Spinocan ${ }^{\circledR}$ needle (1820 inches) was used and introduced. The tip of the needle, identified within the lesion with the help of CT. FNAC was taken and both dry and wet slides were prepared and sent to the pathology department. The results obtained by MDCT were analysed and compared with histopathological findings done by CT guided FNAC.

\section{Results}

Among the 100 patients included in this study, the maximum age distribution was between the age group of 40-89 years with a mean age of 65 years. Gender-wise, $25 \%$ of patients were females and $75 \%$ were males. Most common presenting symptom was cough with expectoration (79\%), weight loss (63\%), dyspnoea (55\%), 
chest pain (54\%), anorexia (39\%) and haemoptysis (36\%) followed by fever (16\%), hoarseness of voice $(12 \%)$ and dysphagia (1\%). The distribution of different test modalities is shown in Table 1 . Among all the patients $66 \%$ of lesions were located in right side lung and $34 \%$ of lesions were left in location. Of all, $2 \%$ patients had lesions less than $3 \mathrm{~cm}, 11 \%$ patients had lesion between $3-4 \mathrm{~cm}, 19 \%$ patients had lesion between $4-5 \mathrm{~cm}$, $26 \%$ patients had lesion between $5-7 \mathrm{~cm}$ and 42 $\%$ patients had lesion greater than $7 \mathrm{~cm}$. Many of these patients also presented with enlarged lymph nodes, most commonly mediastinal (73\%) followed by subcarinal (51 \%), hilar (44\%) and supraclavicular (4\%) lymph nodes.

Table 1: Diagnostic methods and test results

\begin{tabular}{lcc}
\hline Diagnostic Method & Malignant & Benign \\
\hline X-Ray & 77 & 23 \\
\hline CT-Scan & 87 & 13 \\
\hline FNAC & 88 & 12 \\
\hline
\end{tabular}

CT: computed tomography; FNAC: Fine needle aspiration cytology;

Patients also presented with complications and mediastinal and nodal involvement of nodules as shown in Figure 1.

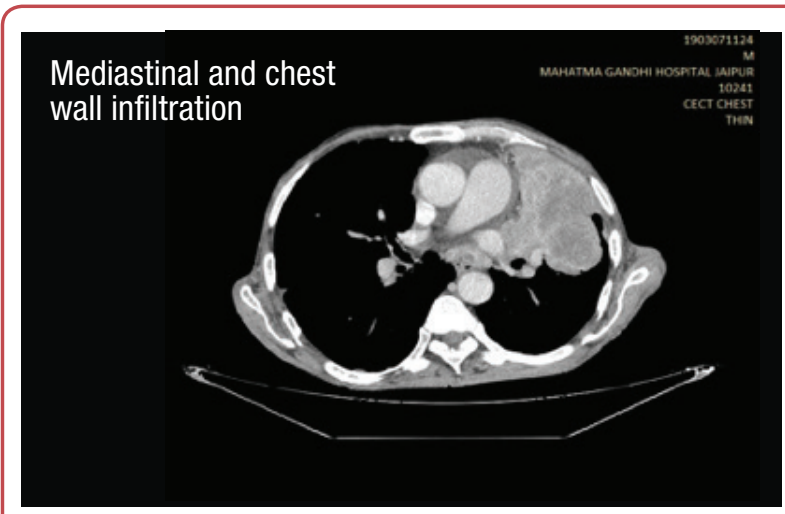

(a)

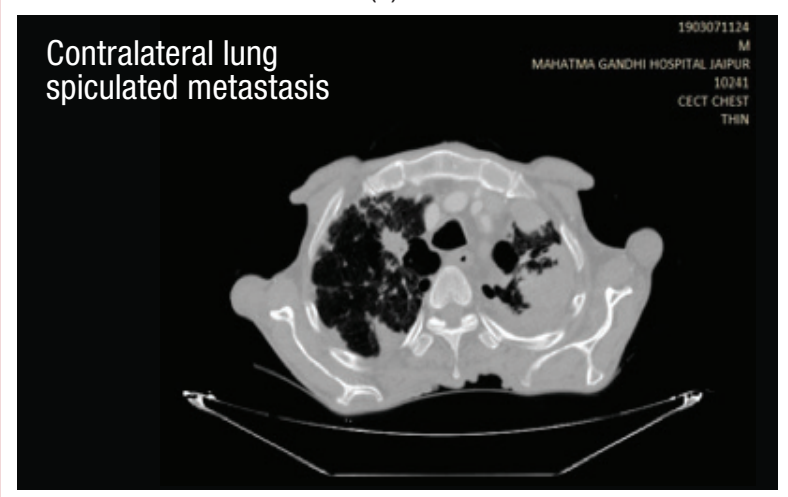

(b)

Figure 1: (a) Contrast enhanced computed tomography (CECT) chest axial scan showing chest wall and mediastinal invasion by mass. (b) CECT chest axial view lung window showing contralateral lung metastasis as spiculated nodular margins.
In this study the most common histological findings of lung nodules analysis were adenocarcinoma (41\%) (Figure 2) followed by others as shown in Table 2. Among the 100 patients $58 \%$ had lesions located peripherally while $42 \%$ had central lesions. Among the central lesions, $45.23 \%$ were squamous cell carcinoma ( $\mathrm{n}=19), 19.04 \%$ were adenocarcinoma as well as small cell carcinoma respectively ( $n=8), 4.76 \%$ cases were of undifferentiated large cell carcinoma and metastatic nodule, respectively $(n=2)$ while $7.14 \%$ were benign nodules $(\mathrm{n}=3)$. Among the peripherally situated lesions $56.89 \%$ were adenocarcinoma $(\mathrm{n}=33)$, $8.62 \%$ were metastatic nodule $(n=5), 6.89 \%(n$ $=4$ ) were squamous cell carcinoma and undifferentiated large cell carcinoma, $5.17 \%$ were small cell carcinoma $(\mathrm{n}=3)$, while $15.51 \%$ of lesions were benign $(n=9)$. Histopathological findings related to gender are shown in Table 3.

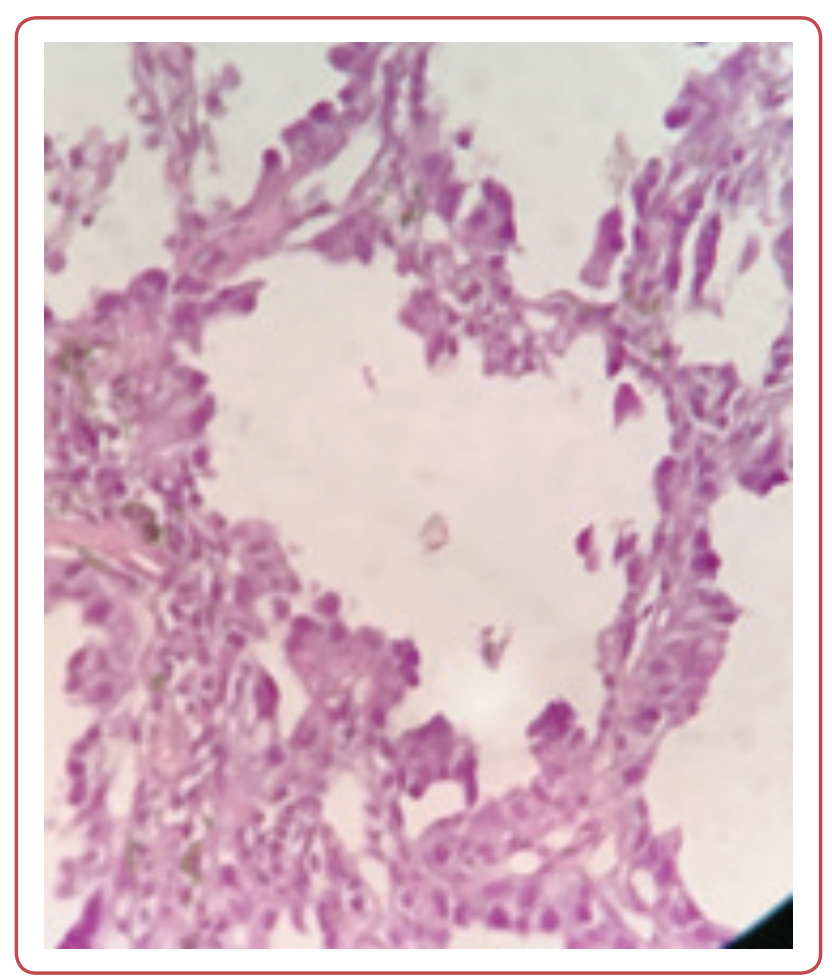

Figure 2: Histopathological findings of lung nodule - adenocarcinoma

Table 2: Histopathological findings of lung nodules

\begin{tabular}{lclc}
\hline $\begin{array}{l}\text { Malignant } \\
\text { pathology }\end{array}$ & N & $\begin{array}{l}\text { Benign } \\
\text { pathology }\end{array}$ & N \\
\hline Adenocarcinoma & 41 & Tubercular granuloma & 5 \\
\hline $\begin{array}{l}\text { Squamous cell } \\
\text { carcinoma (SCC) }\end{array}$ & 23 & $\begin{array}{l}\text { Adenoma } \\
\text { Hamartoma }\end{array}$ & 4 \\
\hline Small cell carcinoma & 11 & & 3 \\
\hline Metastasis & 7 & & \\
\hline $\begin{array}{l}\text { Undifferentiated large } \\
\text { cell carcinoma (LCC) }\end{array}$ & 6 & & \\
\hline
\end{tabular}


Table 3: Histopathological findings related to gender

\begin{tabular}{lrrrr}
\hline \multirow{2}{*}{$\begin{array}{l}\text { Histopathological } \\
\text { findings }\end{array}$} & \multicolumn{2}{c}{ Male } & \multicolumn{2}{c}{ Female } \\
\cline { 2 - 5 } & $\mathbf{N}$ & $\%$ & $\mathbf{N}$ & $\%$ \\
\hline Adenocarcinoma & 29 & 38.67 & 12 & 48.00 \\
\hline $\begin{array}{l}\text { Squamous cell } \\
\text { carcinoma (SCC) }\end{array}$ & 21 & 28.00 & 2 & 8.00 \\
\hline Small cell carcinoma & 7 & 9.33 & 4 & 16.00 \\
\hline Metastatic nodules & 4 & 5.33 & 3 & 12.00 \\
\hline $\begin{array}{l}\text { Undifferentiated large cell } \\
\text { carcinoma (LCC) }\end{array}$ & 6 & 8.00 & 0 & 0 \\
\hline Benign lesions & 8 & 10.67 & 4 & 16.00 \\
\hline Total & 75 & 100.00 & 25 & 100.00 \\
\hline
\end{tabular}

In presented study, $31 \%$ of patients were non-smokers, and $69 \%$ were smokers. Histopathological findings related to smoking status is shown in Table 4.

Table 4: Histopathological findings related to tobacco-smoking status

\begin{tabular}{lrrrrr}
\hline $\begin{array}{l}\text { Histopathological } \\
\text { findings }\end{array}$ & \multicolumn{2}{c}{ Non-smokers } & \multicolumn{2}{c}{ Smokers } \\
\cline { 2 - 5 } & N & $\%$ & N & $\%$ \\
\hline Adenocarcinoma & 17 & 54.84 & 24 & 34.78 \\
\hline $\begin{array}{l}\text { Squamous cell } \\
\text { carcinoma (SCC) }\end{array}$ & 3 & 9.68 & 20 & 28.99 \\
\hline Small cell carcinoma & 3 & 9.68 & 8 & 11.59 \\
\hline Metastatic nodules & 2 & 6.45 & 5 & 7.25 \\
\hline $\begin{array}{l}\text { Undifferentiated large cell } \\
\text { carcinoma (LCC) }\end{array}$ & 0 & 0 & 6 & 8.69 \\
\hline Benign lesions & 6 & 19.35 & 6 & 8.69 \\
\hline Total & 31 & 100.00 & 69 & 100.00 \\
\hline
\end{tabular}

The comparative evaluation of CT and CT guided FNAC for diagnosis of lung nodules is shown in Table 5.

Table 5: Comparison of computed tomography (CT) diagnosis with histopathological diagnosis of lung nodules

\begin{tabular}{|c|c|c|c|c|}
\hline & \multicolumn{4}{|c|}{ Histopathological diagnosis for lung cancer } \\
\hline & & Yes & No & Total \\
\hline \multirow{3}{*}{$\begin{array}{l}\text { CT diagnosis for } \\
\text { lung cancer }\end{array}$} & Yes & 84 (True positive) & 3 (False positive) & 87 \\
\hline & No & 4 (False negative) & 9 (True negative) & 13 \\
\hline & & 88 & 12 & 100 \\
\hline
\end{tabular}

Table 6: Sensitivity, specificity, positive predictive value, negative predictive value and accuracy of computed tomography (CT) to diagnose lung nodules

\begin{tabular}{lc}
\hline Validity Test & Percent \\
\hline Sensitivity & $95.45 \%$ \\
\hdashline Specificity & $75.00 \%$ \\
\hline Positive predictive value & $96.00 \%$ \\
\hline Negative predictive value & $69.00 \%$ \\
\hdashline Accuracy & $93.00 \%$ \\
\hline
\end{tabular}

CT was a highly sensitive (95.45 \%) and moderately specific (75\%) test and also had a high positive predictive value $(96 \%)$ to diagnose malignant lung nodule as shown in Table 6.

\section{Discussion}

Lung masses whether asymptomatic or presenting with various symptoms have always been challenging entities for both clinicians and radiologists. Many diagnostic modalities and various techniques and approaches have been put forward from time to time. MDCT in the present scenario opened a new horizon for evaluation of intrathoracic masses without any invasive procedure. The present study was undertaken to establish the role of CT and CT guided fine needle aspiration cytology in lung masses.

In this study mean age of the patients was in concordance with study by Gangopadhyay et $\mathrm{al}^{4}{ }^{4}$ Dharmaraj et al, ${ }^{5}$ Ahmed et al, ${ }^{6}$ Gupta et al, ${ }^{7}$ Indiranarayan et al, ${ }^{8}$ Saha et al, ${ }^{9}$ Singh et al, ${ }^{10}$ while it was contrary to study done by Mundal et $\mathrm{al}^{11}$ and Mukherjee et al. ${ }^{12}$ In the present study there were $75 \%$ male patients out of 100 patient. That result is similar to findings of Gangopadhyay et $\mathrm{al}^{4}{ }^{4}$ Gadodiya et $\mathrm{al}^{13}$ and Saha et $a l,{ }^{9}$ while in some studies $^{5,7,8}$ the preponderance is very high ie more than $80 \%$ were male patients. In this study $61 \%$ of males and $92 \%$ of females were smokers. High level of association between smoking and occurrence of lung nodules was observed. Similar findings were seen in study done by Meena et al, ${ }^{5}$ Narayan et al, ${ }^{8}$ where $71.36 \%$ and $65 \%$ patients were smokers, respectively. The most common presentation of patient was cough with expectoration. Some other symptom like anorexia, fever, haemoptysis, hoarseness of voice and dysphagia were also present in some patients but to a lesser extent. Similar findings were observed in studies by other researchers. ${ }^{5,14,15}$ Out of 100 patients with lung nodule - with X-ray $77 \%$, with CT scan $87 \%$ and with FNAC $88 \%$ cases were reported malignant and rest were benign. Also, $66 \%$ of lung nodules were found in the right lung and only 34 $\%$ were present in left lung. Similar findings were seen in study done by Ahmed et $\mathrm{al}^{6}$ (45 \% right, $31 \%$ left lung), Mundal et $\mathrm{al}^{11}$ (72 \% right, $52 \%$ left lung) and Saha et al. ${ }^{9}$ Fifty-eight percent of nodules had peripheral location while $42 \%$ were located centrally. This is in concordance with the study done by Adaikkalavan et al, ${ }^{16}$ Biswas et al, ${ }^{17}$ Narayanswami et al. ${ }^{8}$ Maximum lung nodules in this study were more than $7 \mathrm{~cm}$ in size. This suggest that most of the lung nodules express symptoms in patient in their later stages of life, when the size of the lung nodule have already 
been increased. Similar findings were found in literature. 7, 9, 12,13 Patients with lung nodules also had various types of lymphadenopathy. Out of all patients $73 \%$ patient had enlarged mediastinal lymph nodes, $51 \%$ had subcarinal and $44 \%$ had hilar lymph node involvement. There were similar findings seen in study done by Yadav et al. ${ }^{18}$ The amount of enhancement of 100 lung nodules were studied by measuring the CT numbers of both benign and malignant nodules on both pre contrast scan and post contrast scan showing maximum enhancement. There was no statistically significant difference between heterogeneity of contrast enhancement. In the present study contrast enhancement was only showed by malignant lesion that helps in identification of lesion easily. The most common histopathological subtype was adenocarcinoma which accounted for $41 \%$ cases. This is in concordance with studies done by Shad et $\mathrm{al}_{,}{ }^{19}$ Modi et $\mathrm{al},{ }^{20}$ Babu et $\mathrm{al}^{21}$ Gangopadhyay et $\mathrm{al}^{4}$ that showed that there was an increasing trend in the incidence of adenoma, contrary to the studies done by Adaikkalavan et al, ${ }^{16}$ Rawat et $\mathrm{al}_{,}{ }^{15}$ Saha et al, ${ }^{9}$ Ahmed et al, ${ }^{6}$ Narayan et al. ${ }^{8}$ In all these studies squamous cell carcinoma was the most predominant subtype. Adenocarcinoma was seen more at peripheral location (56.84\%), than central (19.04\%). Small cell carcinoma was also more in central location (9.04\%) while large cell carcinoma was seen both in central (4.76\%) and peripheral location (6.89\%) equally. Similar findings were seen in the study done by Narayan et $a .^{8}$ In this study there is evidence of strong association between smoking and occurrence of adenocarcinoma and squamous cell carcinoma. Similar results were obtained in study by Krishnamurthy et $\mathrm{al}^{22}$ Arora et $\mathrm{al}^{3}$ and Meena et al. ${ }^{5}$ The present study showed that MDCT is highly sensitive (95.45\%) and moderately specific (75 $\%)$ and also has a high positive predictive value (0.96) in diagnosis of lung nodules accurately. In a study done by Mukherjee et $\mathrm{al}^{12}$ there was $97.7 \%$ sensitivity and $100 \%$ specificity for CT guided FNAC as a diagnostic procedure. Overall occurrence for cytological subtyping was $95 \%$. Similarly in study done by Meena et $\mathrm{al}^{5}$ there was $96.23 \%$ sensitivity and $87.50 \%$ specificity for CT as a diagnostic procedure.

\section{Conclusion}

CT is a highly sensitive and moderately specific diagnostic modality and also has a high positive predictive value to diagnose lung nodules accurately. In addition to morphological evaluation, CT provides information about staging of the disease. CT guided FNAC of lung nodule is a safe, minimal invasive procedure with a high diagnostic accuracy. The use of CT - guided FNAC in hilar and mediastinal nodules can avoid unnecessary exploratory surgery for staging and also diagnosis is made with lesser cost. It provides very early diagnosis and exact sub classification of various lung nodules on the basis of histopathology. Benign lesions like tuberculosis, lung cyst, pneumonitis etc can also be diagnosed with certainty by this technique. The shortcomings in the diagnosis can be prevented by proper clinical and radiological correlation.

\section{Acknowledgements}

None.

\section{Conflict of interest}

None.

\section{References}

1. Siegel RL, Miller KD, Jemal A. Cancer statistics, 2017. CA Cancer J Clin 2017 Jan;67(1):7-30.

2. Batra P, Brown K, Aberle DR, Young DA, Steckel R. Imaging techniques in the evaluation of pulmonary parenchymal neoplasms. Chest 1992 Jan;101(1):239-43.

3. Barta JA, Powell CA, Wisnivesky JP. Global epidemiology of lung cancer. Ann Glob Health 2019 Jan 22;85(1):8. doi: 10.5334/aogh.2419.

4. Gangopadhyay M, Chakrabarti I, Ghosh N, Giri A. Computed tomography guided fine needle aspiration cytology of mass lesions of lung: Our experience. Indian J Med Paediatr Oncol 2011 Oct;32(4):192-6.

5. MeenaD, Singh Godara C, Saxena S, Khokhar H, Gupta A, Lal B. Role of multi detector computed tomography in evaluation and staging of bronchogenic carcinoma with its histopathological correlation. IOSR-JDMS 2019;18(5):28-35. 
6. Ahmed Z, Israt T, Raza AM, Hossain SA, Shahidullah M. CT Guided FNAC of lung mass- a retrospective study of disease spectrum. J Histopath Cytopath 2018 Jul;2 (2):109113.

7. Gupta DK, Gupta S, Kukkar S. Radio pathological correlation of lung masses: a prospective study of 100 cases. IJMSE 2016;3(2):196-205.

8. Narayanaswamy I, Jayaram N, Ashwathappa S. Multidetector row computed tomography (MDCT) evaluation of bronchogenic carcinoma and histopathological correlation. J Med Imaging 2015;3(4):82-8.

9. Saha A, Kumar K, Choudhuri MK. Computed tomography-guided fine needle aspiration cytology of thoracic mass lesions: A study of 57 cases. J Cytol 2009 Apr;26(2):55-9.

10. Singh JP, Garg L, Setia V. Computed tomography (CT) guided transthoracic needle aspiration cytology in difficult thoracic mass lesions-not approachable by USG. Indian J Radiol Imaging 2004;14:395-400.

11. Mondal SK, Nag D, Das R, Mandal PK, Biswas PK, Osta M. Computed tomogram guided fine-needle aspiration cytology of lung mass with histological correlation: A study in Eastern India. South Asian J Cancer 2013 Jan;2(1):14-8.

12. Mukherjee S, Bandyopadhyay G, Bhattacharya A, Ghosh R, Barui G, Karmakar R. Computed tomography-guided fine needle aspiration cytology of solitary pulmonary nodules suspected to be bronchogenic carcinoma: Experience of a general hospital. J Cytol 2010 Jan;27(1):8-11.

13. Gadodiya K, Patil RN, Kumbhalkar D, Raut WK. Computed tomography guided fine needle aspiration cytology of lung and mediastinal lesions. IJCMR 2019;6(2):B7-B12. DOI: http://dx.doi.org/ 10.21276/ ijcmr.2019.6.2.17.

14. Saket RK, Divyashree. Role of multi-detector computed tomography imaging in patients with clinically suspected lung cancer in Kumaun Region of Uttarakhand (India) JMSCR 2016 Aug;04(08):11839-49.

15. Rawat J, Sindhwani G, Gaur D, Dua R, Saini S. Clinico-pathological profile of lung cancer in Uttarakhand. Lung India 2009 Jul;26(3):74-6.

16. Adaikkalavan C, Sajitha K, Verghese J, Varghese AE. Role of computed tomography in diagnosis of bronchogenic carcinoma with histopathological correlation. JMSCR 2017;5(6):23500-9.

17. Biswas P, Datta A, De A, Sinha LK. Pulmonary mass lesions: CT scan diagnostic-impressions and FNAC diagnoses a correlative study. Int J Med Res Rev 2016;4 (6):1052-6.

18. Yadav D, Yadav N, Goyal R, Romana M. Role of multidetector computed tomography in evaluation of suspected bronchogenic carcinoma. Int J Res Med Sci 2016;4:829-35.

19. Shah D, Shastri M, Patel D, Diwanji N, Desai E, Chitara M, et al. Diagnosis and staging of lung carcinoma with CT scan and its histopathological correlation. Int J Res Med Sci 2017;5:2346-52.

20. Modi M, Nilkanthe R, Kikani A, Trivedi P, Trivedi M, Modi $\mathrm{V}$, et al. Histopathological and CT imaging correlation of various primary lung carcinoma. IOSR-JDMS 2016 Mar;15(3):104-10.

21. Babu S, Kumar S. Multidetector CT evaluation of neoplastic lung lesions with image guided transthoracic tissue sampling. IOSR-JDMS 2016 Feb;15(2):50-3.

22. Krishnamurthy A, Vijayalakshmi R, Gadigi V, Ranganathan R, Sagar TG. The relevance of "Nonsmoking-associated lung cancer" in India: a single-centre experience. Indian J Cancer 2012 Jan-Mar;49(1):82-8.

23. Arora VK, Seetharaman ML, Ramkumar S. Bronchogenic carcinoma; Clinicopathological pattern in south Indian population. Lung India 1990;7:133-8. 